\title{
On the use of the Jander equation in cement hydration modelling
}

\author{
John L. Provis ${ }^{a^{*}}$ \\ ${ }^{a}$ Department of Materials Science \& Engineering, University of Sheffield, United Kingdom \\ Received: 06 July 2016 / Accepted: 26 September 2016 / Published online: 28 October 2016 \\ (C) The Author(s) 2016. This article is published with open access.
}

\begin{abstract}
The equation of Jander [W. Jander, Z. Anorg. Allg. Chem. (1927) 163: 1-30] is often used to describe the kinetics of dissolution of solid cement grains, as a component of mathematical descriptions of the broader cement hydration process. The Jander equation can be presented as $k_{t} / R^{2}=\left[1-(1-\alpha)^{(1 / 3)}\right]^{2}$ where $k$ is a constant, $t$ is time, $R$ is the initial radius of a solid reactant particle, and $\alpha$ is the fractional degree of reaction. This equation is attractive for its simplicity and apparently straightforward derivation. However, the derivation of the Jander equation involves an approximation related to neglect of particle surface curvature which means that it is strictly not correct for anything beyond a very small extent of reaction. This is well documented in the broader literature, but this information has not been effectively propagated to the field of cement science, which means that researchers are continuing to base models on this erroneous equation. It is recommended that if the assumptions of diffusion control and unchanging overall particle size which lead to the selection of the Jander equation are to be retained, it is preferable to instead use the Ginstling-Brounshtein equation [A.M. Ginstling, B.I. Brounshtein, J. Appl. Chem. USSR (1950) 23: 1327-1338], which does correctly account for particle surface curvature without significant extra mathematical complication. Otherwise, it is possible (and likely desirable) to move to more advanced descriptions of particle-fluid reactions to account for factors such as dimensional changes during reaction, and the possibility of rate controlling influences other than diffusion.
\end{abstract}

Keywords: Modeling; Hydration; Shrinking core; Jander equation; Ginstling-Brounshtein equation

\section{Introduction}

The ability to predict the rate, and thus the extent, of hydration of cementitious solid precursors (Portland cement, alternative cements and/or supplementary cementitious materials) lies at the heart of any model which describes the evolution of the chemistry or microstructure of pastes, grouts, mortars or concretes based on these materials. Such models are essential to the description of heat evolution, internal chemical and geometric evolution of hydration products, and performance in service. Many models have been developed and published to describe different aspects of the hydration of various types of cements, with different degrees of chemical and microstructural specificity, and making a wide range of different assumptions regarding the rate-controlling processes and mechanisms $[1,2]$. It is not the purpose of this Letter to enter into the debate regarding the relative merits of each of the specific detailed models that have become available ${ }^{1}$, but rather to provide an assessment of one of the underlying equations which is often incorporated (implicitly or explicitly) into such models: the equation of Jander [3], Eq. 1, used to describe the rate of consumption of a solid precursor grain during a chemical reaction process such as hydration:

$$
\frac{k t}{R^{2}}=\left[1-(1-\alpha)^{1 / 3}\right]^{2}
$$

where $k$ is a constant, $t$ is time, $R$ is the initial radius of a solid reactant particle (e.g. a cement grain), and $\alpha$ is the fractional degree of reaction.

The Jander equation is used to describe the rate of retreat of the surface of a partially reacted spherical solid particle, where the rate-controlling step is the diffusion of reactants through a product layer to an interface at which an (assumed instantaneous) reaction takes place, the product layer directly replacing the space filled by the initial reactant particle with no change in volume. This is a classic example

* Corresponding author: John L. Provis, Department of Materials Science \& Engineering, University of Sheffield, Sir Robert Hadfield Building, Mappin St, Sheffield S1 3JD, United Kingdom, Tel. +44 114222 5490, j.provis@sheffield.ac.uk

${ }^{1}$ It is for this reason, and also to correctly attribute credit (and blame) for the availability of various fundamental equations, that the references cited in this Letter are intentionally biased towards the older literature. Much of the information presented here has been described in various contexts outside the cements literature several decades ago. However, the reappearance of certain errors in modern cement hydration kinetic models necessitates the re-opening of the discussion in this specific context. It is also noted that a far more detailed discussion of various cement hydration models was presented by Xie \& Biernacki [2], and the reader is referred to that document for additional commentary beyond the scope of this Letter. 
of a 'shrinking core reaction' [4-6]. In the specific case of cement chemistry, this would correspond to the limitation of the reaction rate solely by formation of, and diffusion through, the inner product. The importance of this particular type of mechanism is the reason for the inclusion of the Jander model (although in a reorganised and rearranged form) in the now widely-followed formulation of Parrot \& Killoh [7] to describe what is often identified as a diffusioncontrolled regime during the process of cement hydration.

It has also been noted that Jander equation implicitly assumes that all reacting particles are mono-sized, and although corrections explicitly describing certain particle size distributions $[4,8]$ have been introduced, these have not seen widespread use in cement science. Other empirical adaptations of Jander model have been proposed and used in the literature, including either modification of the power law exponent from 2 to another value (introduced in [9] and used by various cements researchers since), or the use of a logarithmic time-dependence (introduced in [10] for glassmelting kinetics and also adopted by various cements researchers); these forms do not have a rigorous analytical derivation and so are of doubtful validity.

The relevance of these physical assumptions to the case of cement hydration has previously been called into question [11], and will undoubtedly vary depending on the specific timeframe, and type of cementitious material, being modelled [7]. There is increasing evidence that a pure diffusion controlled model is not likely to give a realistic description of cement hydration processes, particularly at earlier age, as interfacial and aqueous-phase processes are also influential in determining reaction rates. However, at a more fundamental level and even if the underlying assumptions were taken to be valid, the Jander approach is itself flawed, and this is the topic of the current Letter. It is also noted that other authors have provided discussion along these lines including in the specific context of gas-solid reactions in metallurgy $[4,12]$, and for purely solid-state reactions relevant to pharmaceuticals [13], but the continued usage of the Jander equation by construction materials scientists appears to raise the need for its discussion in a topic-specific journal.

\section{Derivation of the Jander equation, and a (correct) alternative: Ginstling-Brounshtein}

The derivation of the Jander equation commences with the assumptions embodied in Fig. 1.

Based on these assumptions, and $y$ as the thickness of the product layer, the diffusion-controlled mechanism requires:

$\frac{d y}{d t}=\frac{K}{y}$

where $K$ is a constant which effectively incorporates physical and chemical parameters. This can be integrated to yield:

$K t=\frac{y^{2}}{2}$

The extent of reaction of a spherical particle, $\alpha$, is then defined according to Fig. 2.

The fundamental error in the Jander [3] formulation then lies in the next step, where the substitution of $\alpha$ defined in spherical coordinates (Fig. 2) is made into Eq. 3 which was derived in Cartesian coordinates. This substitution, which neglects the surface curvature, uses Eq. 4:

$\frac{y}{R}=1-(1-\alpha)^{1 / 3}$

which when substituted directly into Eq. 3 (and setting $k=2 K$ for simplicity), yields Eq. 1, the Jander formula [3].

To avoid this erroneous substitution, the integration must instead be carried out in spherical coordinates, i.e. with full consideration of surface curvature. Eq. 2 should then be replaced by Eq. 5 [4]:

$-\frac{d r}{d t}=\frac{k^{\prime}}{6}\left(\frac{R}{r(R-r)}\right)$

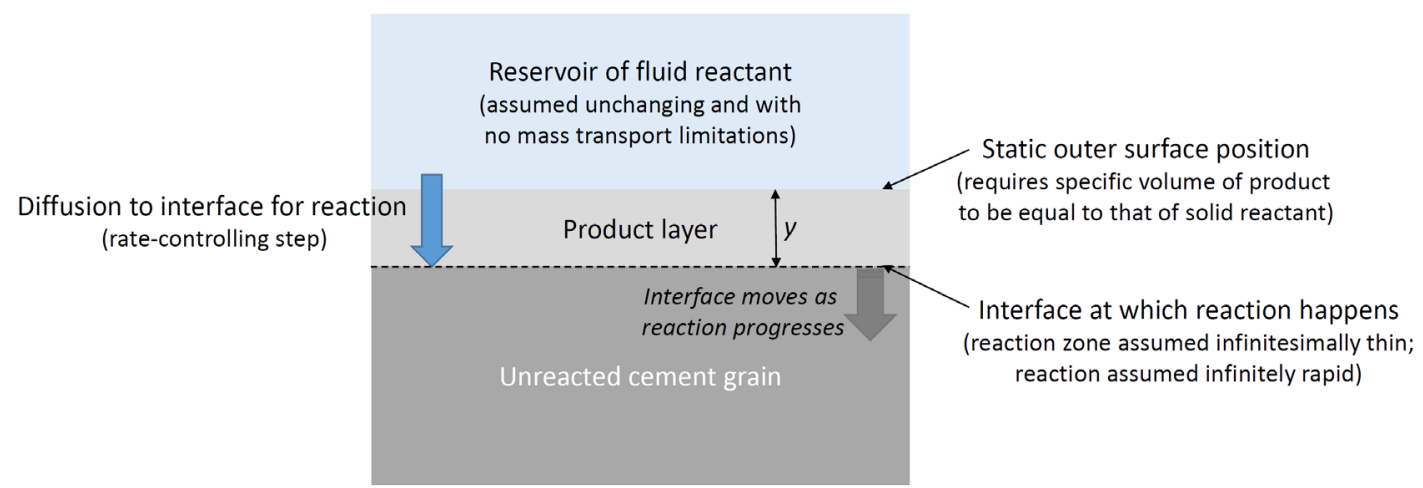

Figure 1. Depiction of the assumptions which are required for the derivation of the Jander equation, and the coordinate $y$ (position of reaction interface) as used in the mathematical derivation. 


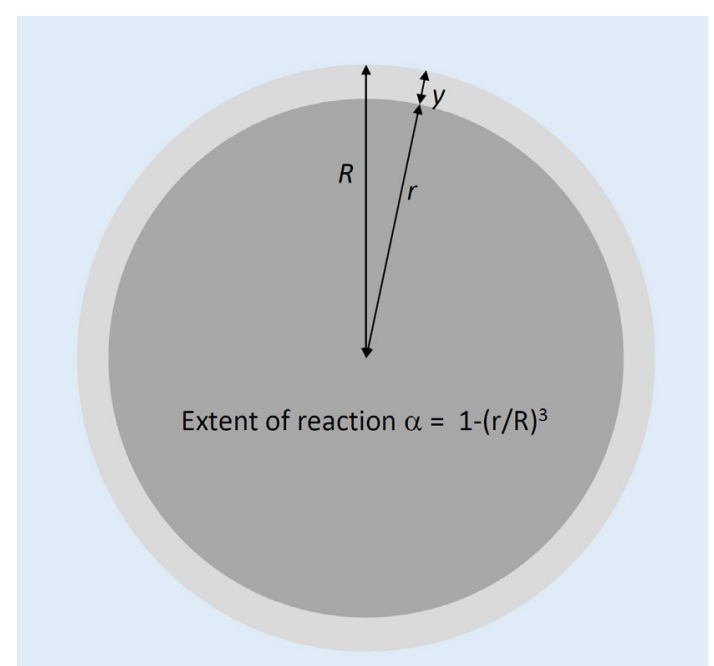

Figure 2. Definition of the extent of reaction $(\alpha)$ for a spherical particle.

Integration of Eq.5 yields Eq.6:

$r^{2}\left(\frac{2 r}{R}-3\right)=k^{\prime} t$

Using the definition of $\alpha$ from Fig. 2 in Eq. 6 then yields the correct description of the particle-fluid reaction assuming rate control by diffusion through a product layer with product volume equal to initial particle volume, known as the Ginstling-Brounshtein equation, Eq. 7 [14]:

$\frac{k t}{R^{2}}=3-2 \alpha-3(1-\alpha)^{2 / 3}$

\section{Why is this important? - comparison between the Jander and Ginstling-Brounshtein models}

Fig. 3 shows a comparison between the predictions of the Jander and Ginstling-Brounshtein models. These models are generally fitted to extent of reaction vs time data, and so to replicate this process while giving a comparison of the models on a realistic basis, they are presented in Fig. 3a normalised to match the times required to reach specified extents of reaction (50, 75 and $100 \%$ ) between the two models. The parameterisation process here is therefore essentially the equivalent of taking a single extent of reaction 'measurement' and fitting both models to that data point, then observing the differences between the models at all reaction extents other than the one used in fitting. Sharp et al. [15] have previously presented this type of analysis of the Jander, Ginstling-Brounshtein and other kinetic equations based solely on matching the time to $50 \%$ reaction; the comparison presented here at different reaction extents provides additional insight into the differences between the models, and the pitfalls which may be encountered in parameterising them for practical use.
This method of presenting the models shows that the main differences between the kinetic predictions of the two models occur at higher reaction extents. This is the most evident when the models are parameterised to give equal times to $100 \%$ reaction (grey dashed vs grey solid line in Fig. 3a); in this case, the predictions for the time required to reach intermediate reaction extents (e.g. 50\% reaction) differ by more than $100 \%$ from the Jander to the GinstlingBrounshtein model. The divergence becomes less notable at intermediate extents of reaction when the models are parameterised using equal time to either $50 \%$ or $75 \%$ reaction (solid and dashed black lines in Flg. 3a, respectively); in such cases, the predictions of both models are rather similar up to a reaction extent of $\sim 80 \%$, but diverge from each other significantly after this. The reason for the divergence between the models at high extents of reaction is related to the geometric errors in the formulation of the Jander model, where both the area and the radius of curvature of the reaction interface become much smaller as the solid reactant is consumed and replaced by a thickening product layer. The neglect of the effects of this curvature is therefore more critical at these higher extents of reaction, and the rate of consumption of the final $20 \%$ of the solid reactant becomes very markedly different between the two model formulations.

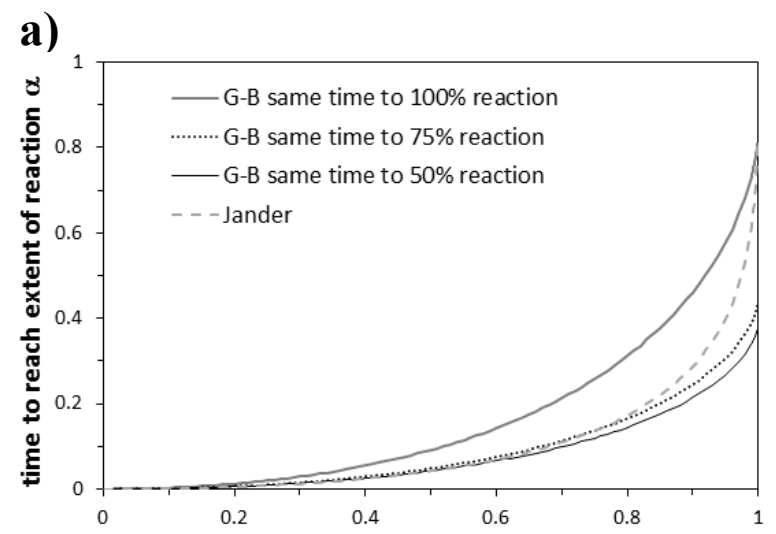

b) $\alpha$

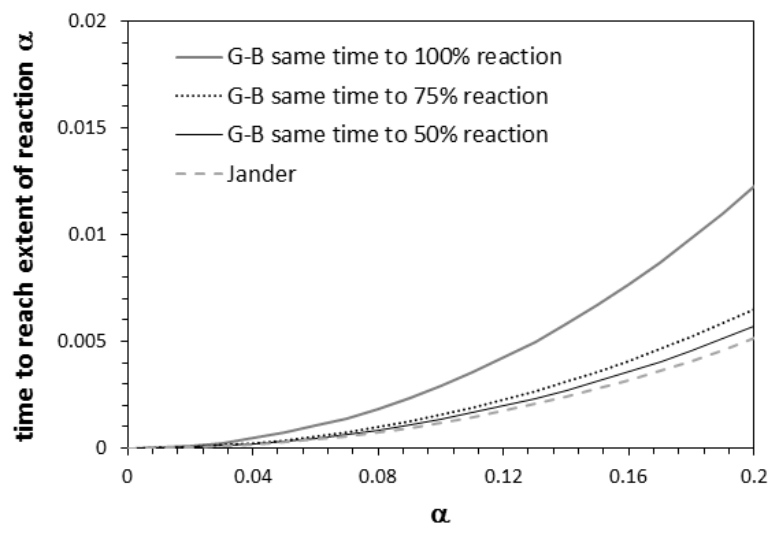

Figure 3. Comparison of the Ginstling-Brounshtein (G-B) and Jander equations: a) normalising each model to give constant times to $50 \%$, $75 \%$ and $100 \%$ extents of reaction; b) expansion of a) in the region of low $\alpha$. 
Fig. $3 b$ provides an expansion of the low- $\alpha$ region of Fig. 3a, showing that there is in fact rather little difference between the predictions of the two models below $20 \%$ reaction extent $(\alpha=0.2)$, as long as the parameterisation is conducted so that the two models are parameterised using data for $75 \%$ reaction or less. However, the fundamental principle that it is better to use an equation that is analytically correct than one that is not, and the negligible extra complexity of the Ginstling-Brounshtein expression compared to the Jander model in terms of inclusion in a model code, would both support the use of the GinstlingBrounshtein model [14] as a preferred description of cement grain consumption during hydration, if the assumptions of diffusion control, constant volume, and solely inner product formation are to be retained. These assumptions themselves have been (rightly) criticised as oversimplifications of the actual process of cement hydration [2], but in instances where it is desirable to build a model from this simplified starting point, it is at least necessary to build it using mathematically correct equations.

\section{Consequences, recommendations and conclusions}

It has previously been proposed by Cable [16], writing in defence of the Jander model, that the model was originally formulated only to describe low extents of reaction, and Fig. $3 b$ does show that fitting the model solely in such a range would give results that are likely to match those of the Ginstling-Brounshtein model to within experimental uncertainty. However, the original Jander paper [3] does present experimental data and model fits for extents of reaction exceeding $80 \%$, which calls this proposal into question.

The extents of reaction of blast furnace slag and fly ashes in practical cementitious blends (w/c 0.40; replacement levels $30-40 \%$ ) have been determined by multiple techniques in a recent RILEM round robin test [17]; at $90 \mathrm{~d}$, slag had reacted around $40-50 \%$ and fly ashes $20-30 \%$. According to the literature survey of Zeng et al. [18], the extent of cement hydration at this age and $\mathrm{w} / \mathrm{c}$ ratio would be expected to be around $70-80 \%$. Thus, based on the findings presented in the previous section, it may be expected that the fitting of either the Jander or Ginstling-Brounshtein models to extent of reaction data obtained at $90 \mathrm{~d}$ or earlier for such materials would give similar predictions of reaction rates during this timeframe. However, there will be instances where much higher extents of reaction are important within meaningful timeframes: Portland cement hydration beyond 12 months, or blending of cementitious systems with silica fume, can lead to extents of reaction (of one or more components) that exceed $90 \%(\alpha=0.90)$. Any application of the Jander model to such cases will introduce severe errors.

Giess [19] also conducted a comparative analysis of the Jander and Ginstling-Brounshtein models, up to $\alpha=0.94$, and applying the Arrhenius temperature-dependence relationship to calculate fundamental rate constants from the model parameters. The use of the Jander equation was also seen to lead to an error of as much as $20 \%$ in the extracted rate constants, particularly at higher extents of reaction.

A further level of development beyond the GinstlingBrounshtein approach was provided by Vallensi [20] and by Carter [12], who each derived equations which account for both curvature of particle surfaces and the potential for formation of a reaction product which does not fill exactly the same space as the original unreacted solid grain. The formulation of Carter [12] presents this in a more userfriendly manner, Eq. 8:

$z+2(1-z) \frac{k t}{R^{2}}=(1+(z-1) \alpha)^{2 / 3}+(z-1)(1-x)^{2 / 3}$

where $z$ is the ratio of the specific volumes of the product and reactant; this is a key parameter which has also been used in microstructurally-based models of cement hydration [21] and can thus be relatively readily obtained from the literature. However, this model does not enable any discrimination between processes taking place in inner and outer product regions. For the specific case of cement hydration, Taplin [22] also derived (and then further developed in subsequent publications) a set of equations involving rate control by diffusion through both inner and outer product regions, which can be reduced to the Ginstling-Brounshtein model in the limit of low influence of the outer product [11].

Xie and Biernacki [2] have described in detail the development of many other models based on different sets of assumptions about controlling mechanisms, geometry and reaction product formation; the available models have gained in sophistication (but not always in clarity regarding the underlying mechanisms) in the past decades as computing power and the ability to store and manipulate three-dimensional reaction simulation snapshots have improved. However, these models are usually based at a fundamental level on simple analytical expressions describing the reaction rate and mechanism associated with each individual cement grain as it hydrates, and the mode and location of growth of the hydrates. It is therefore essential that the underlying physicochemical processes are captured as accurately as is realistically possible. For this reason, the key conclusion of this Letter is that the Jander equation is not suitable for use in describing cement hydration, even if the assumption of diffusion control is to be retained, either as a stand-alone model or as an underpinning component of a broader model structure, as it is derived from a fundamentally flawed mathematical derivation.

\section{Acknowledgements}

The research leading to these results has received funding from the European Research Council under the European Union's Seventh Framework Programme (FP/2007-2013) / ERC Grant Agreement n. 335928 "GeopolyConc". 


\section{References}

[1] J.J. Thomas et al., Modeling and simulation of cement hydration kinetics and microstructure development. Cem Concr Res (2011) 41 (12): 1257-1278.

http://dx.doi.org/10.1016/j.cemconres.2010.10.004

[2] T. Xie, J.J. Biernacki, The origins and evolution of cement hydration models. Comput Concrete (2011) 8 (6): 647-675. http://dx.doi.org/10.12989/cac.2011.8.6.647

[3] W. Jander, Reaktionen im festen Zustande bei höheren Temperaturen. Reaktionsgeschwindigkeiten endotherm verlaufender Umsetzungen. Z anorg allg Chem (in German) (1927) 163 (1): 1-30. http://dx.doi.org/10.1002/zaac.19271630102

[4] H.G. Mcllvried, F.E. Massoth, Effect of particle size distribution on gas-solid reaction kinetics for spherical particles. Ind Eng Chem Fundam (1973) 12 (2): 225-229.

http://dx.doi.org/10.1021/i160046a014

[5] O. Levenspiel, Chemical Reaction Engineering, 3rd Ed. New York, Wiley, 1999.

[6] S. Yagi, D. Kunii, Studies on fluidized roasting of sulphide ore concentrate. (I) Proposed theory of fluidized roasting of sulphide ore concentrate. Kagaku Kikai (1952) 16 (9): 283-288.

[7] L.J. Parrot, D.C. Killoh, Prediction of cement hydration. Br Ceram Trans (1984) 35: 41-53.

[8] S. Miyagi, A criticism on Jander's equation of reaction-rate, considering the statistical distribution of particle size of reacting substance. J Ceram Assoc Japan (1951) 59 (658): 132-135. http://dx.doi.org/10.2109/jcersj1950.59.132

[9] H. Mori, K. Minegishi, Effect of the temperature on the early hydration of the system $3 \mathrm{CaO} \cdot \mathrm{Al}_{2} \mathrm{O}_{3}-\mathrm{CaSO}_{4} \cdot 2 \mathrm{H}_{2} \mathrm{O}-\mathrm{Ca}(\mathrm{OH})_{2}-\mathrm{H}_{2} \mathrm{O}$. Proceedings of the 5 th International Symposium on the Chemistry of Cement. Tokyo, Japan, 1968.

[10] C. Kröger, G. Ziegler, Über die Geschwindigkeiten der zur Glasschmelze führenden Reaktionen. III. (in German) Glastech Ber (1954) 27 (6): 199-212.

[11] A. Bezjak, I. Jelenić, On the determination of rate constants for hydration processes in cement pastes. Cem Concr Res (1980) 10 (4): 553-563. http://dx.doi.org/10.1016/0008-8846(80)90099-X

[12] R.E. Carter, Kinetic model for solid-state reactions. J Chem Phys (1961) 34 (6): 2010-2015. http://dx.doi.org/10.1063/1.1731812

[13] A. Khawam, D.R. Flanagan, Solid-state kinetic models: Basics and mathematical fundamentals. J Phys Chem B (2006) 110 (35): 1731517328. http://dx.doi.org/10.1021/jp062746a

[14] A.M. Ginstling, B.I. Brounshtein, Concerning the diffusion kinetics of reaction in spherical particles. J Appl Chem USSR (1950) 23 (12): 1327-1338.

[15] J.H. Sharp, G.W. Brindley, B.N. Narahari Achar, Numerical data for some commonly used solid state reaction equations. J Am Ceram Soc (1966) 49 (7): 379-382. http://dx.doi.org/10.1111/j.1151-2916.1966.tb13289.x

[16] M. Cable, A century of developments in glassmaking research. J Am Ceram Soc (1998) 81 (5): 1083-1094. http://dx.doi.org/10.1111/j.1151-2916.1998.tb02455.x

[17] P.T. Durdziński et al., Outcomes of the RILEM round robin on degree of reaction of slag and fly ash in composite cements. In: O.M. Jensen, (Ed.). International RILEM Conference on Materials, Systems and Structures in Civil Engineering. Lyngby, Denmark, RILEM, 2016.

[18] Q. Zeng, K. Li, T. Fen-chong, P. Dangla, Determination of cement hydration and pozzolanic reaction extents for fly-ash cement pastes. Constr Build Mater (2012) 27 (1): 560-569.

http://dx.doi.org/10.1016/j.conbuildmat.2011.07.007

[19] E.A. Giess, Equations and tables for analyzing solid-state reaction kinetics. J Am Ceram Soc (1963) 46 (8): 374-376. http://dx.doi.org/10.1111/j.1151-2916.1963.tb11754.x

[20] G. Valensi, Cinétique de l'oxydation de sphérules et de poudres métalliques (in French). C R Acad Sci (1935) 202 (4): 309-312.

[21] D.P. Bentz, Three-dimensional computer simulation of Portland cement hydration and microstructure development. J Am Ceram Soc (1997) 80 (1): 3-21. http://dx.doi.org/10.1111/j.1151-2916.1997.tb02785.x

[22] J.H. Taplin, The temperature coefficient of the rate of hydration of $\beta$ dicalcium silicate. In: E.T. Carlson, H.H. Steinour, (Eds), Proceedings of the 4th International Symposium on the Chemistry of Cement. Washington DC, National Bureau of Standards, 1960. 